\title{
Harmonic Analysis on Torque Ripple of Brushless DC Motor Based on Advanced Commutation Control
}

\author{
Yanpeng Ji $\mathbb{D},{ }^{1}$ Bin Li $\mathbb{D},{ }^{1}$ and Jingcheng Sun ${ }^{2}$ \\ ${ }^{1}$ School of Electrical and Information Engineering, Tianjin University, Tianjin 300072, China \\ ${ }^{2}$ State Grid Zibo Power Supply Company, Zibo 255000, China \\ Correspondence should be addressed to Bin Li; elib@tju.edu.cn
}

Received 29 September 2017; Revised 7 December 2017; Accepted 26 December 2017; Published 1 February 2018

Academic Editor: Carlos-Andrés García

Copyright (C) 2018 Yanpeng Ji et al. This is an open access article distributed under the Creative Commons Attribution License, which permits unrestricted use, distribution, and reproduction in any medium, provided the original work is properly cited.

\begin{abstract}
This paper investigates the relationship between current, back electromotive force (back-EMF), and torque for permanent-magnet brushless DC (PM BLDC) motors under advanced commutation control from the perspective of harmonics. Considering that the phase current is the influencing factor of both torque and torque ripple, this paper firstly analyzes the effects of advanced commutation on phase current and current harmonics. And then, based on the harmonics of the phase current and back-EMF, the torque harmonic expressions are deduced. The expressions reveal the relationship of harmonic order between the torque, phase current, and back-EMF and highlight the different contribution of individual torque harmonic to the total torque ripple. Finally, the proposed harmonic analysis method is verified by the experiments with different speed and load conditions.
\end{abstract}

\section{Introduction}

The brushless DC (BLDC) motors have a wide range of applications in industrial and civil areas due to high power density, high efficiency, simple drive, and high reliability [16]. Electromagnetic torque ripple is an important indicator of motor performance. Compared with permanent-magnet synchronous machines (PMSM), commutation torque ripple of BLDC motors is more serious so as to generate noise and vibration and narrow the scope of high precision and high stability applications $[3,7]$.

Many direct and indirect methods are introduced to reduce the torque ripple. Liu et al. [7] employed a hybrid switching mode to minimize the error between the commanded torque and the actual torque, which did not require the information of the conduction duration and adaptively adjusted phase current to maintain constant torque. Indirect method reduces the torque ripple by making the incoming and outgoing phase currents change at the same rate during the commutation. Chen et al. $[2,3,8]$ adopted three different circuits in front of the inverter to meet the voltage demand of commutation period, so that noncommutation phase current was kept steady and commutation torque ripple was reduced. Shi and Li [4] calculated the duty cycle per phase in a PWM period to keep the same current change rates of incoming and outgoing phases. Advanced commutation can also reduce commutation torque ripple by narrowing the differences of current change rates for incoming and outgoing phases. Considering the signal harmonics of the Hall position sensors, Chiu et al. [5] proposed an improved phase advance circuit to get more accurate advanced angle, which restrained torque ripple and improved the torque performance. Park et al. [6] presented an expression to adjust the advanced commutation angle, which avoided the rotor position error at the reverse motoring mode. In [9], each phase conduction time was extended to broaden the conducting area of phase current and obtain wider speed range and lower torque ripple. A modified driving strategy that consisted of advanced commutation and overlapping method was proposed to suppress the torque ripple [10]. Considering the entire speed range, Jung et al. [11] analyzed the commutation torque ripple depending on three commutation control methods including conventional six-step, advanced commutation method and advanced commutation 


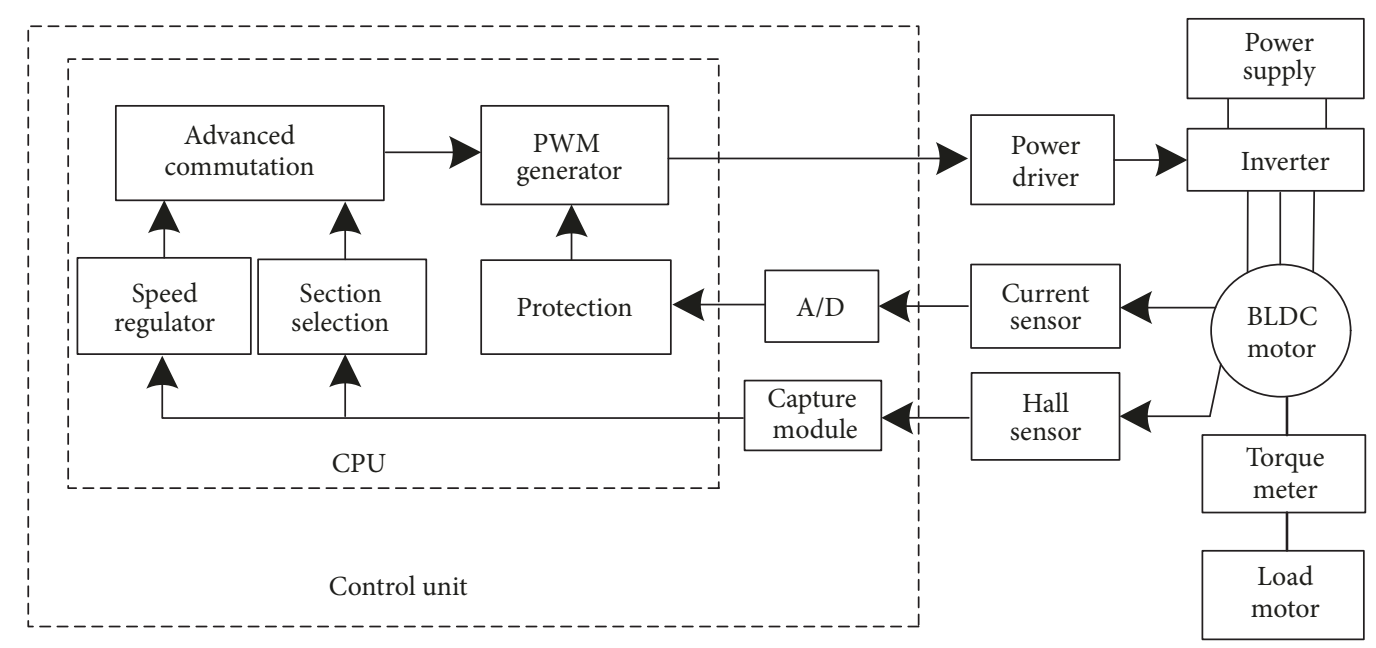

(a)

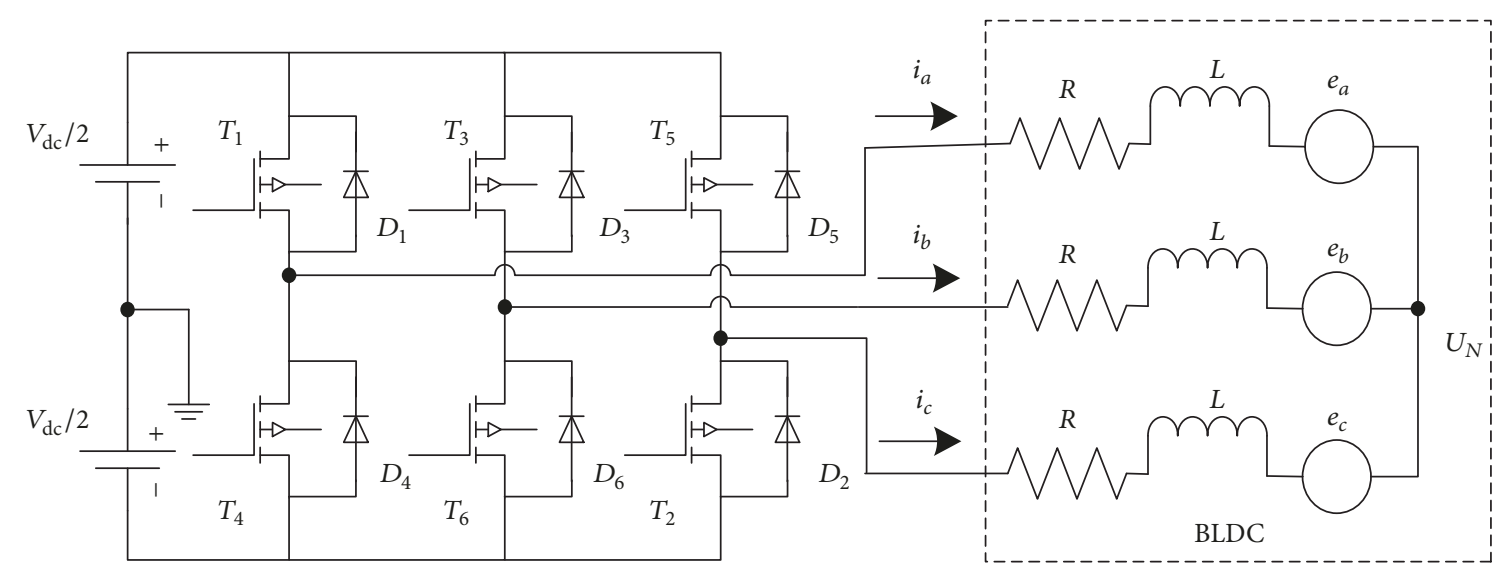

(b)

FIGURE 1: (a) The block diagram of advanced commutation control. (b) The driving circuit and equivalent circuit of the BLDC.

with overlapping method. Then an optimal current vector trajectory was designed based on the three methods to reduce the torque ripple. Considering the nonideal characteristics of BLDC motors, a calculating method of advanced angle was proposed to improve the torque-to-current ratio and efficiency [12]. Given the relationship between the torque and advanced angle, Im et al. [13] solved the differential equations to achieve torque maximization, and a simplified function of advanced angle was presented by curve fitting.

To improve the control performance, more detailed analysis of torque ripple needs to be studied. Zhu et al. [14] investigated the contribution of current harmonics to average torque and torque ripple in switched reluctance machines. Chen [15] proposed an electromagnetic torque model for PMSM and analyzed the influence of current and back-EMF harmonics on torque. $\mathrm{Hu}$ et al. [16] enhanced torque output of a dual three-phase PMSM by injecting the fifth and seventh current harmonics without any hardware reconfiguration. In order to analyze the impacts of actual current and back-EMF waveform, the torque harmonic expressions for six-phase BLDC motor were deduced [17]. However, both the trend of torque harmonics varying with the advanced angle and the effects on torque ripple have not been given.

In this paper, the relationship between current, back-EMF harmonic, and torque harmonic for three-phase BLDC motor with advanced commutation control is presented. Firstly, the influences of advanced commutation on phase current and current harmonics are analyzed. Then, based on the harmonic decomposition of phase current and back-EMF, the torque harmonic expressions that relate to the advanced angle are deduced. These torque harmonics change with advanced angle and make different contribution to torque ripple. Furthermore, the experimental bench is set up to verify the presented analysis.

\section{The Advanced Commutation Control of BLDC Motor}

As to three-phase wye-connected BLDC motor, Figure 1(a) illustrates the block diagram of advanced commutation control and Figure 1(b) shows the driving circuit and equivalent circuit of a BLDC motor. 


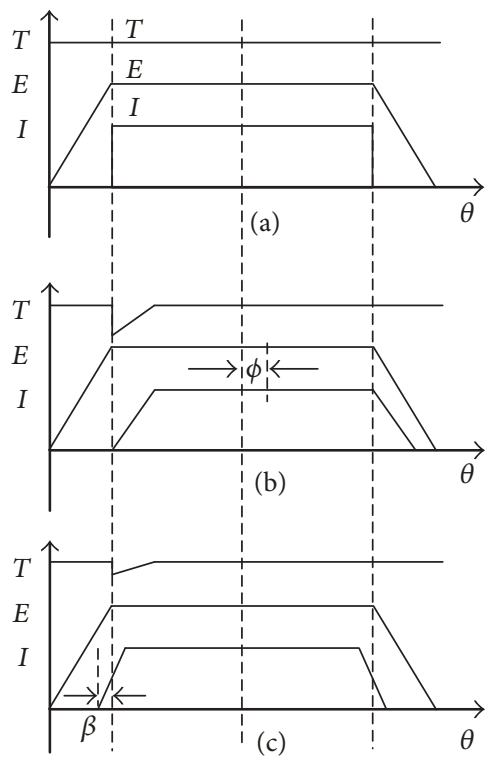

FIGURE 2: The torque, back-EMF, and phase current: (a) ideal case; (b) actual case; (c) advanced $\beta$ electrical angle.

According to the equivalent circuit in Figure 1(b), the phase voltage equations can be written as [18]

$$
\begin{aligned}
{\left[\begin{array}{l}
u_{a} \\
u_{b} \\
u_{c}
\end{array}\right]=} & {\left[\begin{array}{lll}
R & 0 & 0 \\
0 & R & 0 \\
0 & 0 & R
\end{array}\right]\left[\begin{array}{l}
i_{a} \\
i_{b} \\
i_{c}
\end{array}\right]+\left[\begin{array}{lll}
L & 0 & 0 \\
0 & L & 0 \\
0 & 0 & L
\end{array}\right] P\left[\begin{array}{l}
i_{a} \\
i_{b} \\
i_{c}
\end{array}\right] } \\
& +\left[\begin{array}{l}
e_{a} \\
e_{b} \\
e_{c}
\end{array}\right]+\left[\begin{array}{l}
U_{N} \\
U_{N} \\
U_{N}
\end{array}\right]
\end{aligned}
$$

and the equation of the electromagnetic torque is

$$
T_{e}=\frac{\left(e_{a} i_{a}+e_{b} i_{b}+e_{c} i_{c}\right)}{\omega_{m}},
$$

where $u_{a}, u_{b}$, and $u_{c}$ are the terminal phase voltages of threephase windings; $i_{a}, i_{b}$, and $i_{c}$ are phase winding currents; $e_{a}$, $e_{b}$, and $e_{c}$ are trapezoidal back-EMFs; and $L, R, U_{N}$, and $\omega_{m}$ are the stator equivalent inductance, phase resistance, neutral point voltage, and mechanical angular velocity of the BLDC motor, respectively.

Figure 2(a) shows ideal square-wave phase current that is in phase with the corresponding back-EMF. When the motor operates with two-phase windings conducting, no torque fluctuation is generated according to (2). However, torque ripple and the decrease of output torque will be inevitable owing to the lagging quasi-square-wave phase current as shown in Figure 2(b) and become more severe with the increase of speed or load $[19,20]$. This situation can be improved by advancing a commutation angle $\beta$ as shown in Figure 2(c). According to (1) and Figure 2(c), it can be noted that current can be built rapidly as the backEMF has not reached the maximum at the commutating
TABLE 1: The specifications of BLDC motor.

\begin{tabular}{lc}
\hline Parameters & Value \\
\hline Rated power/W & 1200 \\
Rated voltage/V & 24 \\
Resistance/ $\Omega$ & 0.043 \\
Inductance/uH & 15 \\
Pole number & 8 \\
Rated speed/rpm & 3200 \\
\hline
\end{tabular}

time. And the phase current has been close to maximum when the back-EMF gets the reference value. Therefore, advance commutation contributes to the establishment of the incoming phase current.

Essentially, advance commutation changes the amplitude and phase angle of current and then the torque. So it is necessary to analyze and solve the phase currents varying with the advanced angle firstly.

\section{The Motor Performance Analysis under Advanced Commutation Control}

This section studies the phase current and electromagnet torque of BLDC motor. To analyze motor performances, a BLDC motor is selected and the main parameters are shown in Table 1.

3.1. Phase Current Analysis. In advanced commutation control mode, the analytical expressions of phase current can be obtained by referring to [9]. Differential equation of the incoming phase current is calculated as follows:

$$
\begin{aligned}
\frac{d i(t)}{d t}= & {\left[\frac{1}{L}\left(V_{k}+\frac{V_{\mathrm{dc}}}{6}-\frac{2 E}{3}\right)+\frac{4 E}{\pi L} \beta+\frac{4 \omega E}{\pi R}\right] e^{-(R / L) t} } \\
& -\frac{4 \omega E}{\pi R}
\end{aligned}
$$

where $V_{\mathrm{dc}}, E, \omega$, and $\beta$ are the supply voltage, back-EMF amplitude, electrical angular velocity, and advanced angle, respectively. $V_{k}=V_{\mathrm{dc}}\left(S_{a}-0.5\right)$ is the average input voltage and $S_{a}$ is switching function of one phase and is set as 0 or 1 .

Based on (3), it can be concluded that advanced angle increases the coefficient of the exponent, which shortens the time to reach the reference current. The decrease of $L$ is also beneficial for the establishment of incoming phase current. However, the increase of back-EMF $E$, which is proportional to the electrical angular speed, causes gentle slope and deviation compared with the ideal square-wave current. If the speed and supply circuits are confirmed for a BLDC motor, advanced angle would have an important effect on phase current.

Figure 3 shows the commutation process from $B$-phase to $C$-phase. Compared to the ideal commutation, the actual case decreases noncommutating phase current due to the smaller current slew rate of incoming phase than that of outgoing phase when $V_{\mathrm{dc}}<4 E$ is true $[4,8]$.

$A$-phase currents with the variation of advanced angle are shown in Figure 4. As can be seen, the phase current 


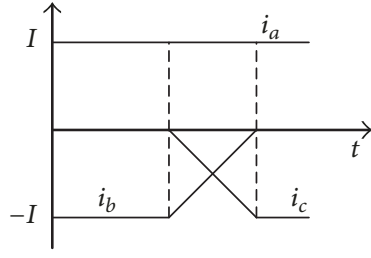

(a)

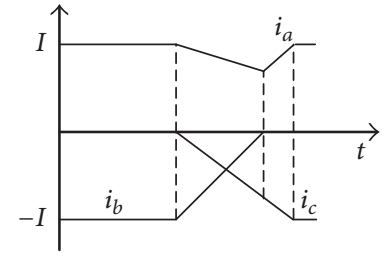

(b)

Figure 3: The commutation from $B$-phase to $C$-phase: (a) ideal case $\left(V_{\mathrm{dc}}=4 E\right)$; (b) actual case $\left(V_{\mathrm{dc}}<4 E\right)$.

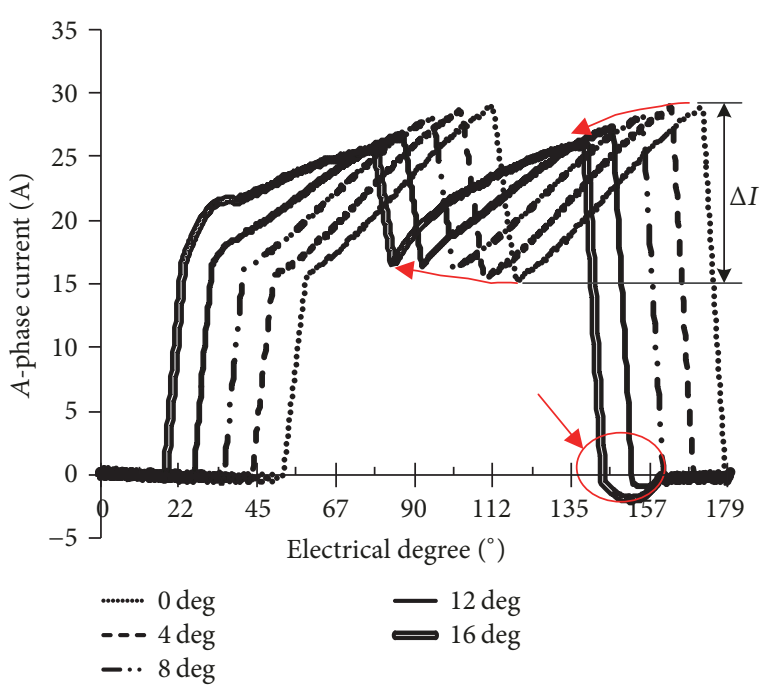

FIGURE 4: The phase currents varying with the advanced angles within half electrical cycle.

has a maximal pulsation $\Delta I$ when advanced angle is zero. With the increase of advanced angle, current slew rate of incoming phase grows, which reduces the current pulsation of noncommutating phase and contributes to the suppression of torque ripple according to Figure 3 and (2). However, as advanced angle increases gradually to $12^{\circ}$ electrical angle, negative $A$-phase current is passing through the freewheel diode when $A$-phase is switched off, which causes the current distortion circled by a red solid line and is harmful for torque.

The harmonic components of quasi-square-wave phase current can be obtained based on harmonic decomposition. Considering the complexity of initial phase angles of current harmonics, the $A$-phase current expressed by a series of harmonics can be simplified as [17]

$$
\begin{aligned}
i_{a}(t)= & I_{1} \sin (\omega t-\phi)+I_{5} \sin 5(\omega t-\phi) \\
& +I_{7} \sin 7(\omega t-\phi)+I_{11} \sin 11(\omega t-\phi)+\cdots,
\end{aligned}
$$

where $\phi$ is the lagging angle of phase current compared with back-EMF and $I_{1}, I_{5}, I_{7}$, and $I_{11}$ are the amplitudes of fundamental harmonic and the 5th, 7th, and 11th current harmonics, respectively. In those current harmonics, the current harmonic with the same frequency as quasi-square wave is defined as fundamental component of phase current.
Similarly, the fundamental components of back-EMF and torque can be also defined.

Figure 5 shows the initial 20 harmonics of the phase currents under different advanced angles. To clarify the detail, the fundamental harmonic and the 5th, 7th, and 11th harmonics are also highlighted in Figure 5. It shows that the amplitude of those main harmonics firstly decreases and then increases when the advanced angle increases.

3.2. Commutation Torque Ripple Analysis. To analyze the torque harmonics and torque ripple, the ideal back-EMF is also decomposed as follows:

$$
e_{a}(t)=E_{1} \sin \omega t+E_{3} \sin 3 \omega t+E_{5} \sin 5 \omega t+\cdots .
$$

The initial phase angles of back-EMF harmonics are 0 due to the symmetry of ideal back-EMF waveform and the origin setup in Figure 2.

Then on the basis of (2) and the trigonometric function equations, the electromagnetic torque can be expressed by the DC component and a series of harmonics [17]:

$$
\begin{aligned}
T_{e}= & T_{0}+T_{6 c} \cos 6 \omega t+T_{6 s} \sin 6 \omega t+T_{12 c} \cos 12 \omega t \\
& +T_{12 s} \sin 12 \omega t+\cdots,
\end{aligned}
$$

where $T_{0}$ is the DC component (expected average torque) and $T_{k c}$ and $T_{k s}$ are the cosine amplitude and sine amplitude of the $k$ th torque harmonic, $k=6,12,18, \ldots$. The electromagnet torque is the sum of expected average torque and unexpected torque harmonics. These harmonics cause the variation of average torque with the time. They are the source of torque ripple and eliminated objectives.

According to (6) and (7), it can be found that the fundamental harmonic of torque does not exist and the torque only contains the 6th and its multiple orders' harmonics, which are related to back-EMF harmonics, phase current harmonics, and the lagging angle of current. Because the higher the harmonic orders of phase current and back-EMF are, the smaller their amplitudes are, thus the 6th and the 12th torque harmonics and the first 20 current harmonics are only considered.

Based on (7), the torque harmonics varying with the advanced angles are calculated and displayed in Figure 6(a), including DC component $T_{0}$, the cosine component of the 6 th harmonic $T_{6 c}$, the sine component of the 6th harmonic $T_{6 s}$, 


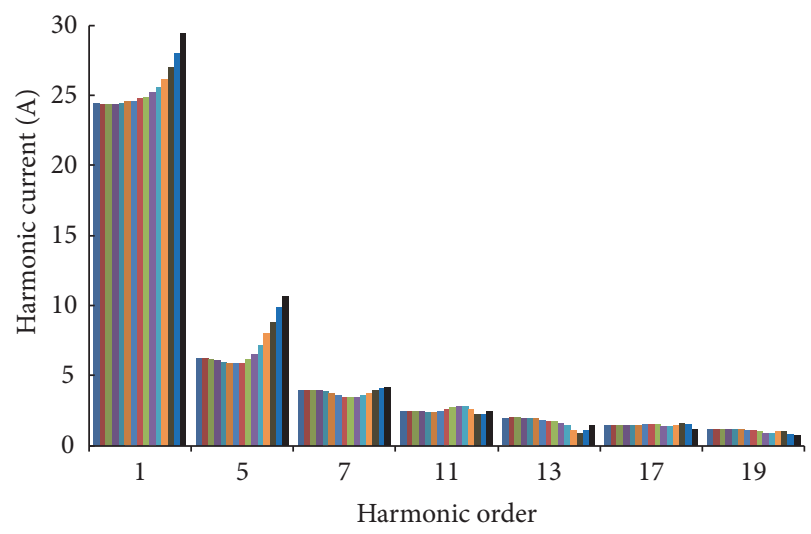

$\begin{array}{llr}-0 \operatorname{deg} & -10 \mathrm{deg} & -20 \mathrm{deg} \\ -2 \mathrm{deg} & -12 \mathrm{deg} & =22 \mathrm{deg} \\ -4 \mathrm{deg} & =14 \mathrm{deg} & -24 \mathrm{deg} \\ -6 \mathrm{deg} & -16 \mathrm{deg} & -26 \mathrm{deg} \\ -8 \mathrm{deg} & -18 \mathrm{deg} & -28 \mathrm{deg}\end{array}$
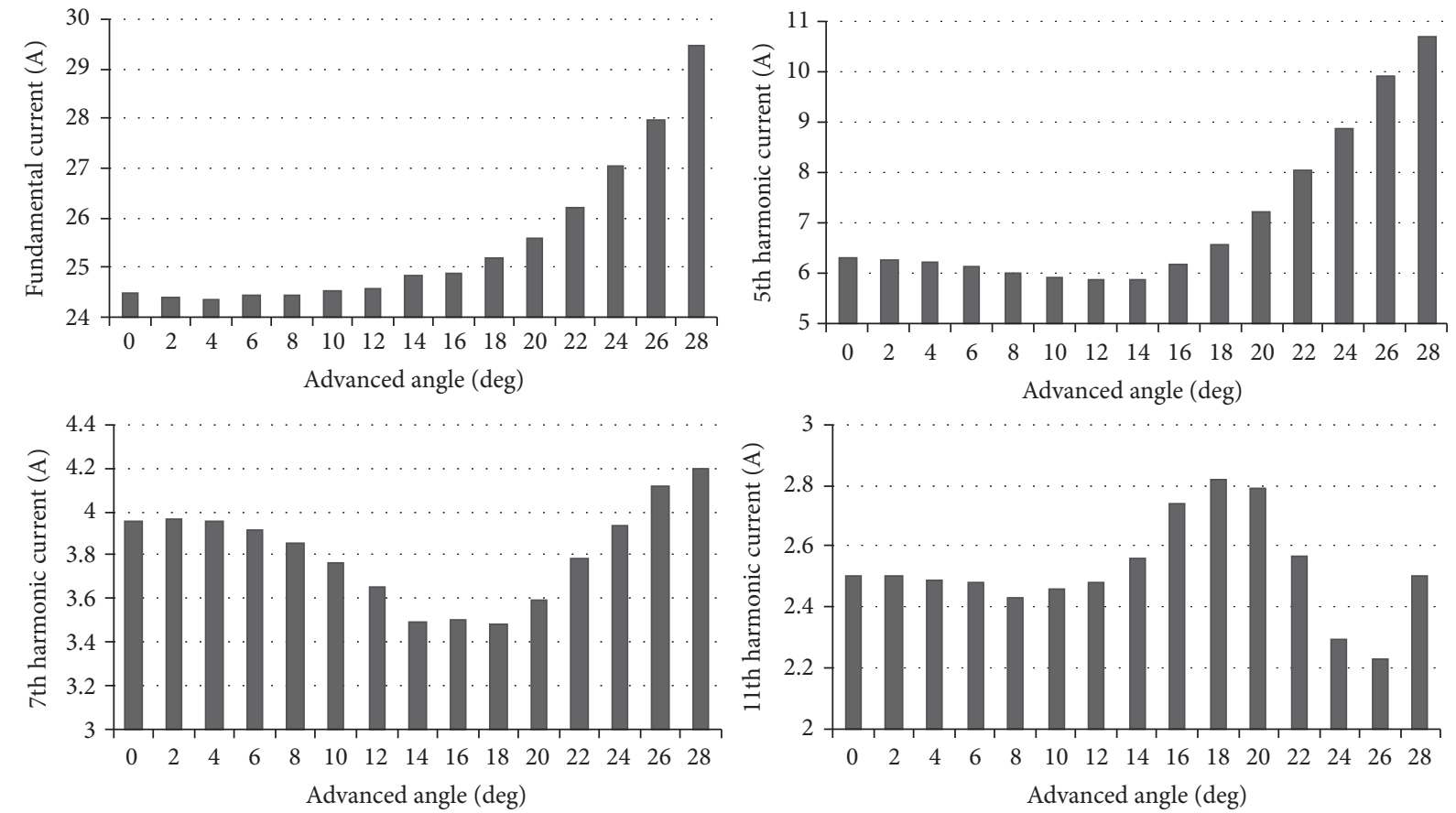

FIgURE 5: Harmonics of phase current varying with the advanced angles.

the cosine component of the 12th harmonic $T_{12 c}$, and the sine component of the 12th harmonic $T_{12 s}$.

$$
\begin{aligned}
T_{0} & =\frac{3}{2 \omega_{m}}\left(E_{1} I_{1} \cos \phi+E_{5} I_{5} \cos 5 \phi+E_{7} I_{7} \cos 7 \phi\right. \\
& \left.+E_{11} I_{11} \cos 11 \phi+\cdots\right), \\
T_{6 c} & =\frac{3}{2 \omega_{m}}\left[I_{1}\left(E_{7}-E_{5}\right) \cos \phi+I_{5}\left(E_{11}-E_{1}\right) \cos 5 \phi\right. \\
& +I_{7}\left(E_{13}+E_{1}\right) \cos 7 \phi+I_{11}\left(E_{17}+E_{5}\right) \cos 11 \phi \\
& +I_{13}\left(E_{19}+E_{7}\right) \cos 13 \phi+I_{17}\left(E_{23}+E_{11}\right) \cos 17 \phi
\end{aligned}
$$

$$
\begin{aligned}
& \left.+I_{19}\left(E_{25}+E_{13}\right) \cos 19 \phi+\cdots\right], \\
T_{6 s} & =\frac{3}{2 \omega_{m}}\left[-I_{1}\left(E_{7}+E_{5}\right) \sin \phi-I_{5}\left(E_{11}+E_{1}\right) \sin 5 \phi\right. \\
& -I_{7}\left(E_{13}-E_{1}\right) \sin 7 \phi-I_{11}\left(E_{17}-E_{5}\right) \sin 11 \phi \\
& -I_{13}\left(E_{19}-E_{7}\right) \sin 13 \phi-I_{17}\left(E_{23}-E_{11}\right) \sin 17 \phi \\
& \left.-I_{19}\left(E_{25}-E_{13}\right) \sin 19 \phi-\cdots\right], \\
T_{12 c} & =\frac{3}{2 \omega_{m}}\left[I_{1}\left(E_{13}-E_{11}\right) \cos \phi\right. \\
& +I_{5}\left(E_{17}-E_{7}\right) \cos 5 \phi+I_{7}\left(E_{19}-E_{5}\right) \cos 7 \phi
\end{aligned}
$$




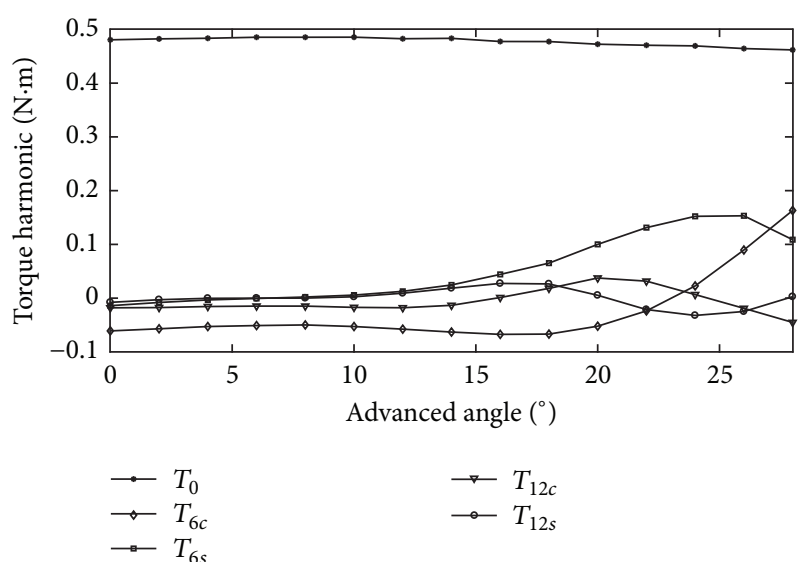

(a)

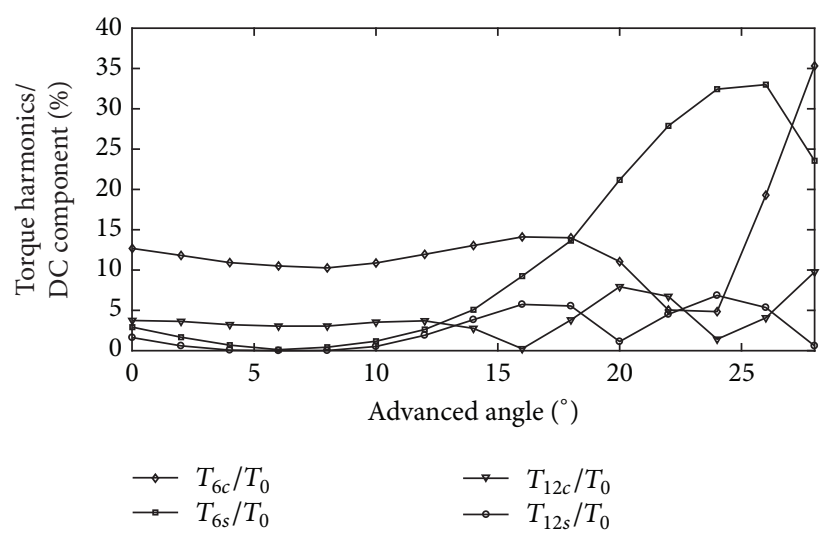

(b)

Figure 6: (a) Torque harmonic amplitude diagram. (b) The ratio of torque harmonics to DC component.

$$
\begin{aligned}
& +I_{11}\left(E_{23}-E_{1}\right) \cos 11 \phi+I_{13}\left(E_{25}+E_{1}\right) \cos 13 \phi \\
& +I_{17}\left(E_{29}+E_{5}\right) \cos 17 \phi+I_{19}\left(E_{31}+E_{7}\right) \cos 19 \phi \\
& +\cdots] \\
T_{12 s} & =\frac{3}{2 \omega_{m}}\left[-I_{1}\left(E_{13}+E_{11}\right) \sin \phi\right. \\
& -I_{5}\left(E_{17}+E_{7}\right) \sin 5 \phi-I_{7}\left(E_{19}-E_{5}\right) \sin 7 \phi \\
& -I_{11}\left(E_{23}+E_{1}\right) \sin 11 \phi-I_{13}\left(E_{25}-E_{1}\right) \sin 13 \phi \\
& -I_{17}\left(E_{29}-E_{5}\right) \sin 17 \phi-I_{19}\left(E_{31}-E_{7}\right) \sin 19 \phi \\
& -\cdots] .
\end{aligned}
$$

As shown in Figure 6(a), when the advanced angle changes, the DC component keeps nearly stable and reaches the maximum at the optimal angle ( $8^{\circ}$ electrical angle). At the optimal advanced angle, the amplitudes of the 6th and 12th sinusoidal harmonic components are almost zero, but the absolute values of the 6th and 12th cosine harmonic components are not minimum. As the advanced angle increases, the 6th and 12th harmonics of the torque will change and result in serious torque ripple.

Figure 6(b) gives the ratio of the torque harmonics to DC component based on (7). When advanced angle is less than $18^{\circ}$ electrical angle, the fluctuation is mainly caused by the 6 th cosine component and reaches about $13 \%$ of DC component; from $18^{\circ}$ to $28^{\circ}$, the ripple resulting from the 6th sinusoidal harmonic increases rapidly to $35 \%$ of average torque. There are two reasons contributing to the rapid increase of the 6th sinusoidal component. One is that the phase current changes from lagging behind the back-EMF to being ahead of it and the advanced angle increases. The other one is that phase current harmonics also increase with the growth of the advanced angle given in Figure 5.

Moreover, it can be also seen that each harmonic has the optimal value in Figure 6(b). For the harmonic component

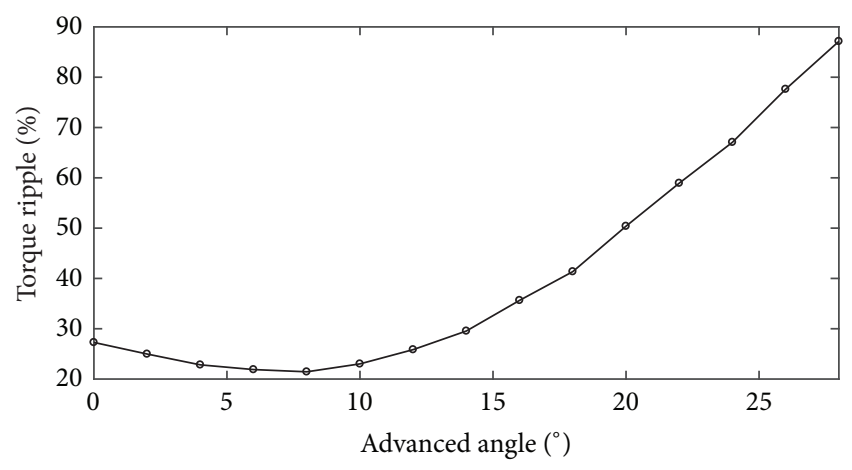

FIgURE 7: Torque ripple changing with advanced angle.

$T_{6 c}$, the optimal value can be obtained when advanced angle is $22^{\circ}$ electrical degree. The component $T_{6 c}$ decreases to only $5 \%$ of the average torque. If the commutation control advances $16^{\circ}$ electrical degree, the harmonics component $T_{12 c}$ will not contribute to the torque ripple. For the harmonic components $T_{6 s}$ and $T_{12 s}$, the optimal values can be reached only when the advanced angle is $6^{\circ}$ electrical degree. So, the optimal values for different harmonic components are acquired at different advanced angles.

The coefficient of torque ripple can be defined as [21]

$$
T_{r}=\frac{2 \sqrt{\sum\left(T_{k c}^{2}+T_{k s}^{2}\right)}}{T_{0}} .
$$

According to (8), Figure 7 shows the torque ripple varying with advanced angle. As shown in Figure 7, the torque ripple value is minimum at the optimal advanced angle. Then the amplitude of the torque ripple increases as the advanced angle grows. For instance, the ripple will be about $50 \%$ of the average torque at 20 o electrical angle. So when the advanced commutation control is employed, the large advanced angle may cause the motor torque ripple and noise, which affect the motor performance greatly and even cause damage. 


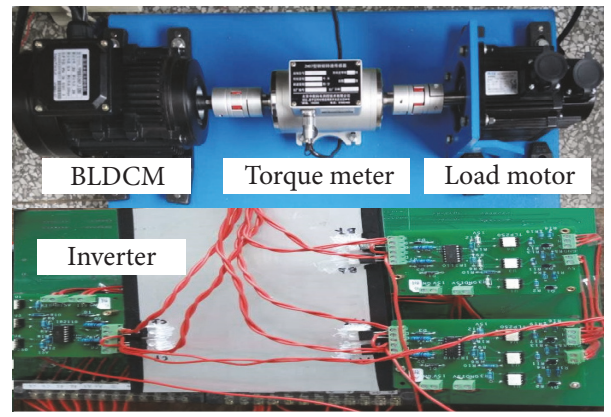

FIGURE 8: The configuration of experimental equipment.

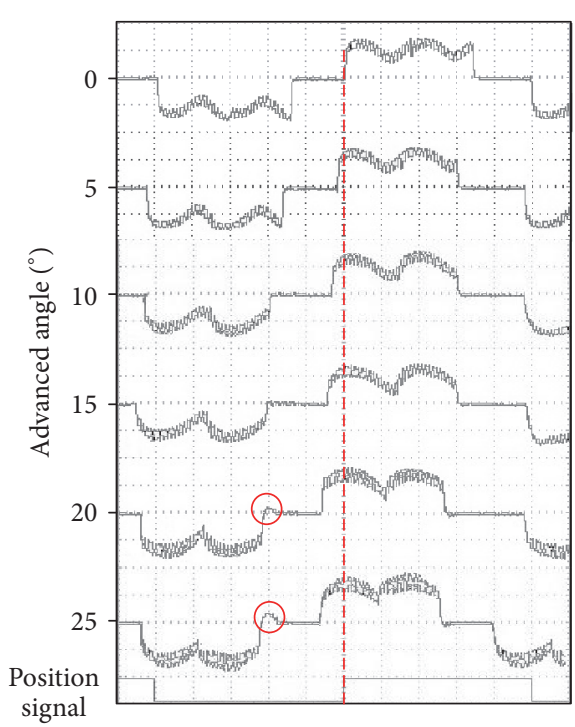

(a)

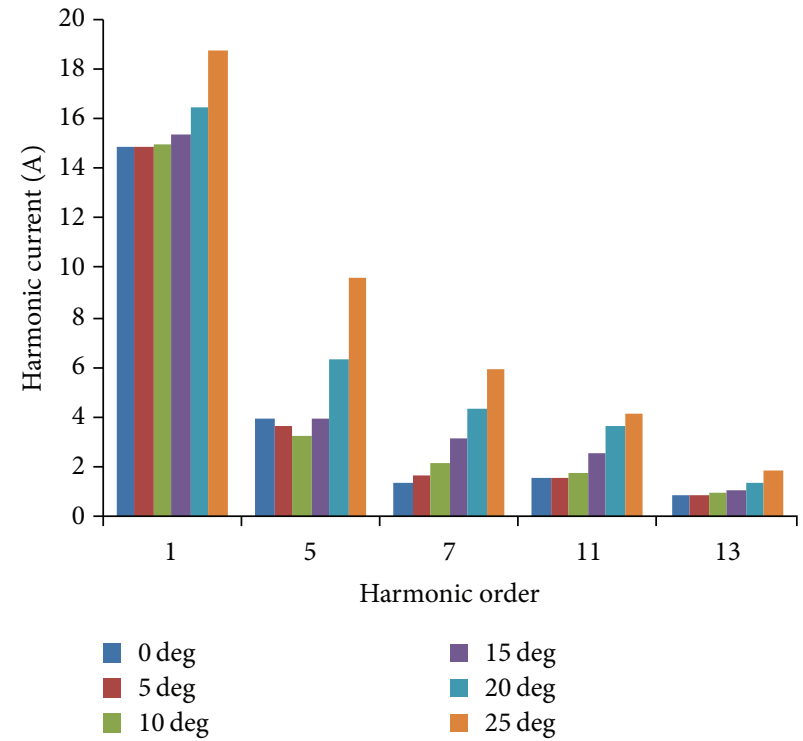

(b)

Figure 9: Experimental waveforms in $1500 \mathrm{rpm}$ and $0.8 \mathrm{Nm}$ condition with different advanced angles: (a) phase currents; (b) current harmonics.

Torque harmonic analysis reveals the source of the torque ripple and can provide some suggestions for reducing the torque ripple. Taking the component $T_{6 c}$ as an example, the terms $I_{5}\left(E_{11}-E_{1}\right) \cos 5 \phi$ and $I_{7}\left(E_{13}-E_{1}\right) \cos 7 \phi$ dominate the amplitude of $T_{6 c}$. Therefore, the 5 th and 7 th harmonics of phase current should be designed to make the sum of these two terms approximate 0 . And the optimization of the 5 th and 7 th back-EMF harmonics to weak the term $I_{1}\left(E_{7}-E_{5}\right) \cos \phi$ is also beneficial. These can be achieved by improving the motor design $[22,23]$ and current control strategies $[24,25]$.

\section{Experiment and Results Analysis}

In order to verify the presented analysis, the experiment is designed with a BLDC motor and compares with analytical method. Matlab 2014 is adopted as the analytical software, and Figure 8 shows the configuration of experimental equipment. The main parameters of the motor have been given in
Table 1. The system control is implemented on the KEAZ128 platform and the motor is powered by a $24 \mathrm{~V}$ lithium battery. The phase currents are measured via utilizing two current Hall sensors, CHF-25P. And the phase current results are displayed and stored though an oscilloscope.

Four working conditions are carried out including $1000 \mathrm{rpm}$ case with $0.8 \mathrm{Nm}$ load, $1500 \mathrm{rpm}$ case with $0.4 \mathrm{Nm}$ load, $1500 \mathrm{rpm}$ case with $0.8 \mathrm{Nm}$ load, and $1500 \mathrm{rpm}$ case with $1.5 \mathrm{Nm}$ load. Taking $1500 \mathrm{rpm}$ condition with $0.8 \mathrm{Nm}$ load as an example, Figure 9(a) shows the comparison of $A$-phase currents with different advanced angles. It can be seen that advanced commutation causes the change of phase current so that torque harmonics and commutation torque ripple will be affected. When advanced angle is greater than $20^{\circ}$ electrical angle and $A$-phase is switched off, the phase current passes through the freewheel diode, which causes the current distortion circled by a red solid line and is harmful for torque. Figure 9(b) shows the current harmonics decomposed from 


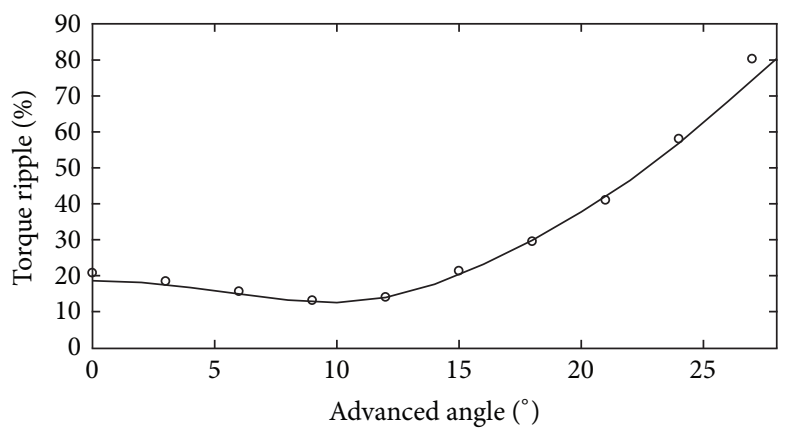

- Analytical

- Experimental

(a)

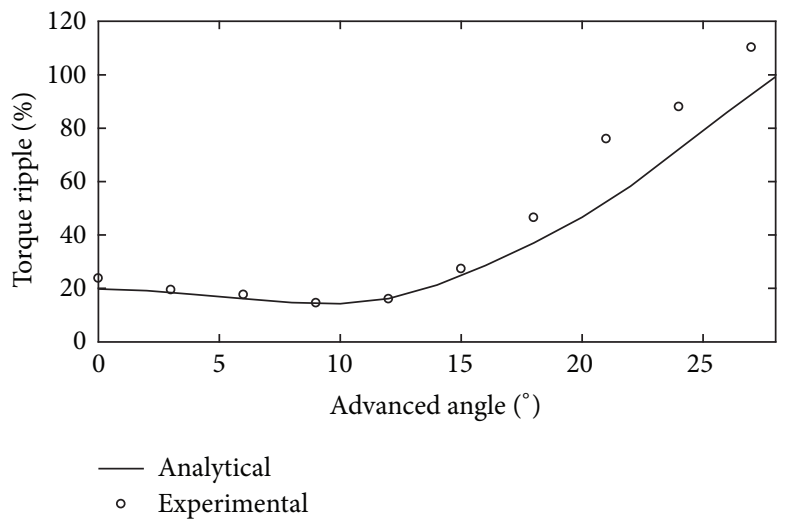

(c)

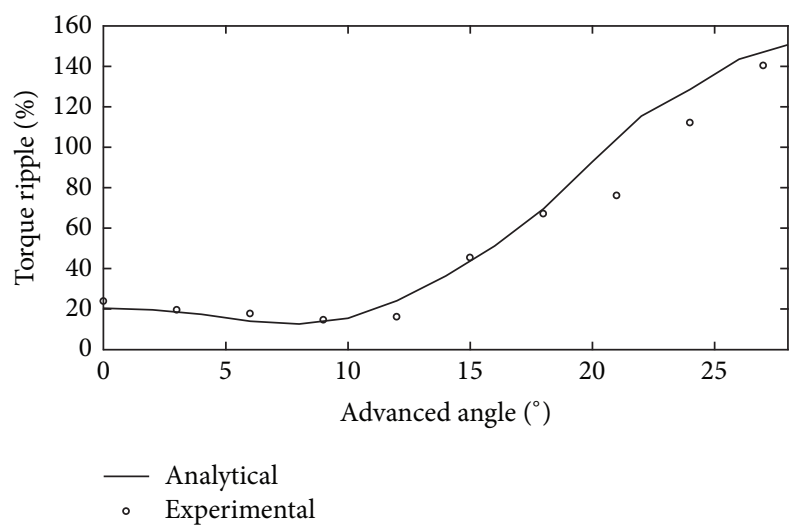

(b)

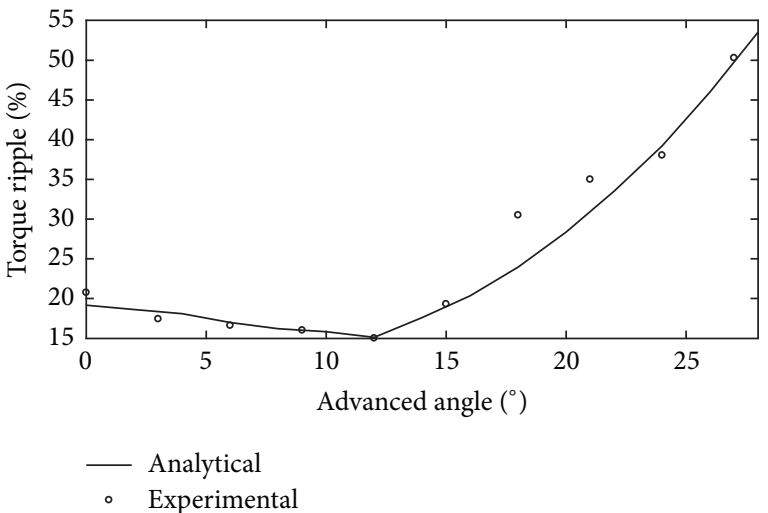

(d)

FIGURE 10: The waveforms of torque ripple with the variation of advanced angle from the experimental and analytical methods: (a) 1000 rpm and $0.8 \mathrm{Nm}$ condition; (b) $1500 \mathrm{rpm}$ and $0.4 \mathrm{Nm}$ condition; (c) $1500 \mathrm{rpm}$ and $0.8 \mathrm{Nm}$ condition; (d) $1500 \mathrm{rpm}$ and $1.5 \mathrm{Nm}$ condition.

the phase currents in Figure 9(a). It is obvious that advanced angle contributes to the variation of phase current, that is, the amplitude of current harmonics essentially.

Then according to the torque harmonic expressions, torque ripple results of four conditions are given in Figure 10 by employing both experimental and analytical methods. It can be found that experimental result matches well with analytical result when advanced angle is less than $15^{\circ}$ electrical angle for four operating conditions. However, there are some differences between experimental and analytical results after $15^{\circ}$ electrical angle in Figure 10.

For the same load, $0.8 \mathrm{Nm}$, Figures 10 (a) and 10 (c) compare two speed cases, $1000 \mathrm{rpm}$ and $1500 \mathrm{rpm}$. It can be found that a lower speed has a smaller commutation torque ripple, which is consistent with the analysis about (3). For Figures 10(b), 10(c) and 10(d), three load cases with the same speed are compared. The optimal advanced angle that minimizes commutation torque ripple changes with the load of BLDC motor. Moreover, when load is $0.4 \mathrm{Nm}$, large advanced angle causes serious commutation torque ripple and affects the motor performance. Therefore, it is concluded that advanced commutation method is more suitable for heavy load applications.

\section{Conclusion}

The paper studies the relationship between current, backEMF, and torque for three-phase BLDC motor with advanced commutation control. The effects of advanced commutation on phase current and current harmonics are studied firstly. Then, on the basis of current and back-EMF harmonics, the torque harmonics and torque ripple are analyzed and calculated. These results reveal the trend of torque harmonics varying with the advanced angle and emphasize the different contribution of individual torque harmonic to the total torque ripple. These results and analysis may be useful for the control strategies and motor design, which will improve the motor performance.

\section{Conflicts of Interest}

The authors declare that they have no conflicts of interest.

\section{References}

[1] D. Gerada, A. Mebarki, N. L. Brown, C. Gerada, A. Cavagnino, and A. Boglietti, "High-speed electrical machines: Technologies, trends, and developments," IEEE Transactions on Industrial Electronics, vol. 61, no. 6, pp. 2946-2959, 2014. 
[2] W. Chen, Y. Liu, X. Li, T. Shi, and C. Xia, "A novel method of reducing commutation torque ripple for brushless DC motor based on Cuk converter," IEEE Transactions on Power Electronics, vol. 32, no. 7, pp. 5497-5508, 2017.

[3] Z. Chen, H. Zhang, X. Liu, H. Hu, J. Zhao, and C. Gao, "A new method to suppress the commutation torque ripple for BLDC motor based on ZETA converter," in Proceedings of the 6th International Conference on Power Electronics Systems and Applications, PESA 2015, Hong Kong, December 2015.

[4] J. Shi and T.-C. Li, "New method to eliminate commutation torque ripple of brushless DC motor with minimum commutation time," IEEE Transactions on Industrial Electronics, vol. 60, no. 6, pp. 2139-2146, 2013.

[5] C.-L. Chiu, Y.-T. Chen, Y.-H. Shen, and R.-H. Liang, "An accurate automatic phase advance adjustment of brushless DC motor," IEEE Transactions on Magnetics, vol. 45, no. 1, pp. 120126, 2009.

[6] S.-I. Park, T.-S. Kim, S.-C. Ahn, and D.-S. Hyun, "An improved current control method for torque improvement of high-speed BLDC motor," in Proceedings of the Eigtheenth Annual IEEE Applied Power Electronics Conference and Exposition, pp. 294299, USA, February 2003.

[7] Y. Liu, Z. Q. Zhu, and D. Howe, "Commutation-torque-ripple minimization in direct-torque-controlled PM brushless DC drives," IEEE Transactions on Industry Applications, vol. 43, no. 4, pp. 1012-1021, 2007.

[8] T. Shi, Y. Guo, P. Song, and C. Xia, "A new approach of minimizing commutation torque ripple for brushless dc motor based on DC-DC converter," IEEE Transactions on Industrial Electronics, vol. 57, no. 10, pp. 3483-3490, 2010.

[9] J.-J. Moon, W.-S. Im, and J.-M. Kim, "Novel phase advance method of BLDC motors for wide range speed operations," in Proceedings of the 28th Annual IEEE Applied Power Electronics Conference and Exposition, APEC 2013, pp. 2343-2348, USA, March 2013.

[10] M. Taha, A. M. Thabet, and O. A. Mahgoub, "Brushless DC motor drive with minimum torque ripple," in Proceedings of the 18th International Middle-East Power Systems Conference, MEPCON 2016, pp. 888-893, Egypt, December 2016.

[11] S.-Y. Jung, Y.-J. Kim, J. Jae, and J. Kim, "Commutation control for the low-commutation torque ripple in the position sensorless drive of the low-voltage brushless DC motor," IEEE Transactions on Power Electronics, vol. 29, no. 11, pp. 5983-5994, 2014.

[12] C. Shin, C. Choi, and W. Lee, "Advance angle calculation for improvement of the torque-to-current ratio of brushless DC motor drives," in Proceedings of the 2011 2nd International Conference on Advances in Energy Engineering, ICAEE 2011, pp. 1410-1414, Thailand, December 2011.

[13] W.-S. Im, J.-P. Kim, J.-M. Kim, and K.-R. Baek, "Torque maximization control of 3-phase BLDC motors in the high speed region," Journal of Power Electronics, vol. 10, no. 6, pp. 717723, 2010.

[14] Z. Q. Zhu, B. Lee, L. Huang, and W. Chu, "Contribution of current harmonics to average torque and torque ripple in switched reluctance machines," IEEE Transactions on Magnetics, vol. 53, no. 3, pp. 1-9, 2017.

[15] Z. Chen, "Torque ripple analysis with current harmonics in permanent-magnet synchronous machines," in Proceedings of the 2015 IEEE International Magnetics Conference, INTERMAG 2015, China, May 2015.
[16] Y. Hu, Z. Q. Zhu, and M. Odavic, "Torque capability enhancement of dual three-phase PMSM drive with fifth and seventh current harmonics injection," IEEE Transactions on Industry Applications, vol. PP, no. 99, pp. 1-10, 2017.

[17] Y. Rang, H. Xiong, Q. Wu, G. Meng, H. Li, and L. Zhou, "FEM simulation and harmonic torque analysis of six-phase BLDC motor," in Proceedings of the 2011 2nd International Conference on Artificial Intelligence, Management Science and Electronic Commerce, AIMSEC 2011, pp. 3984-3987, China, August 2011.

[18] J. Fang, H. Li, and B. Han, "Torque ripple reduction in BLDC torque motor with nonideal back EMF," IEEE Transactions on Power Electronics, vol. 27, no. 11, pp. 4630-4637, 2012.

[19] R. Carlson, M. Lajoie-Mazenc, and J. C. D. S. Fagundes, "Analysis of torque ripple due to phase commutation in brushless DC machines," IEEE Transactions on Industry Applications, vol. 28, no. 3, pp. 632-638, 1992.

[20] C. K. Lad and R. Chudamani, "A simple overlap angle control strategy for reducing commutation torque ripple in a brushless DC motor drive," Engineering Science and Technology, an International Journal, vol. 20, no. 4, pp. 1406-1419, 2017.

[21] H. Le-Huy, R. Perret, and R. Feuillet, "Minimization of Torque Ripple in Brushless DC Motor Drives," IEEE Transactions on Industry Applications, vol. IA-22, no. 4, pp. 748-755, 1986.

[22] B. Boukais and H. Zeroug, "Magnet segmentation for commutation torque ripple reduction in a brushless DC motor drive," IEEE Transactions on Magnetics, vol. 46, no. 11, pp. 3909-3919, 2010.

[23] Y. Yokoi and T. Higuchi, "Stator design of alternate slot winding for reducing torque pulsation with magnet designs in surfacemounted permanent magnet motors," IEEE Transactions on Magnetics, vol. 51, no. 6, 2015.

[24] T. Nag, S. B. Santra, A. Chatterjee, D. Chatterjee, and A. K. Ganguli, "Fuzzy logic-based loss minimisation scheme for brushless DC motor drive system," IET Power Electronics, vol. 9, no. 8, pp. 1581-1589, 2016.

[25] R. Mikail, I. Husain, Y. Sozer, M. S. Islam, and T. Sebastian, "Torque-ripple minimization of switched reluctance machines through current profiling," IEEE Transactions on Industry Applications, vol. 49, no. 3, pp. 1258-1267, 2013. 


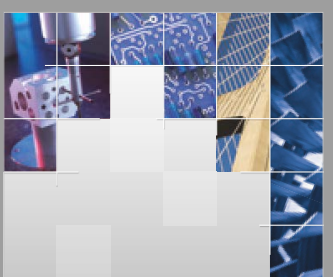

\section{Enfincering}
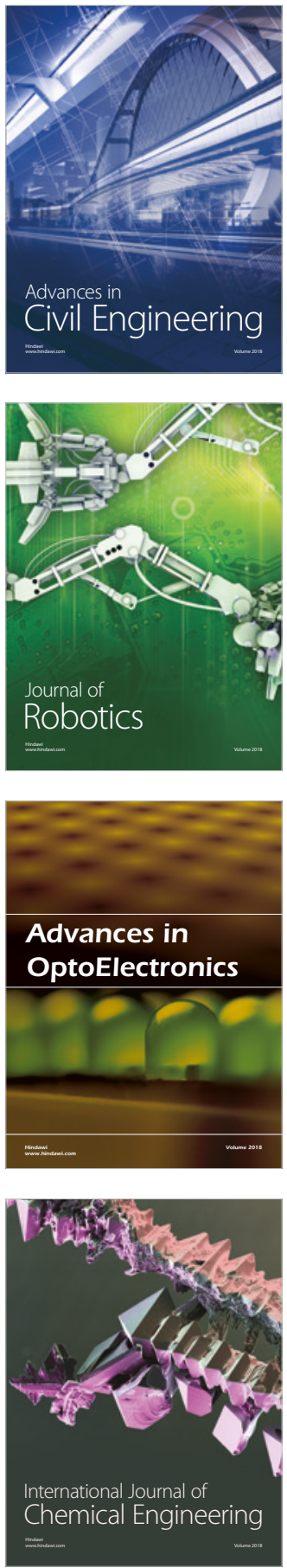

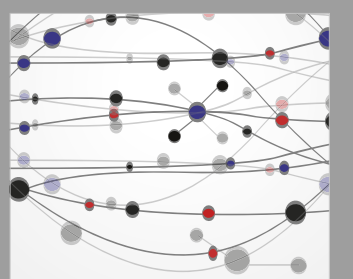

\section{Rotating \\ Machinery}

The Scientific World Journal

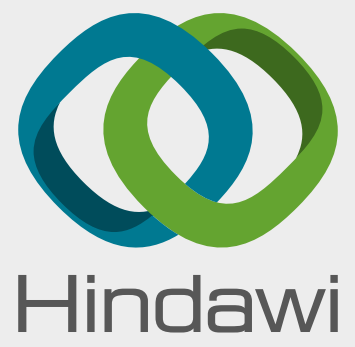

Submit your manuscripts at

www.hindawi.com
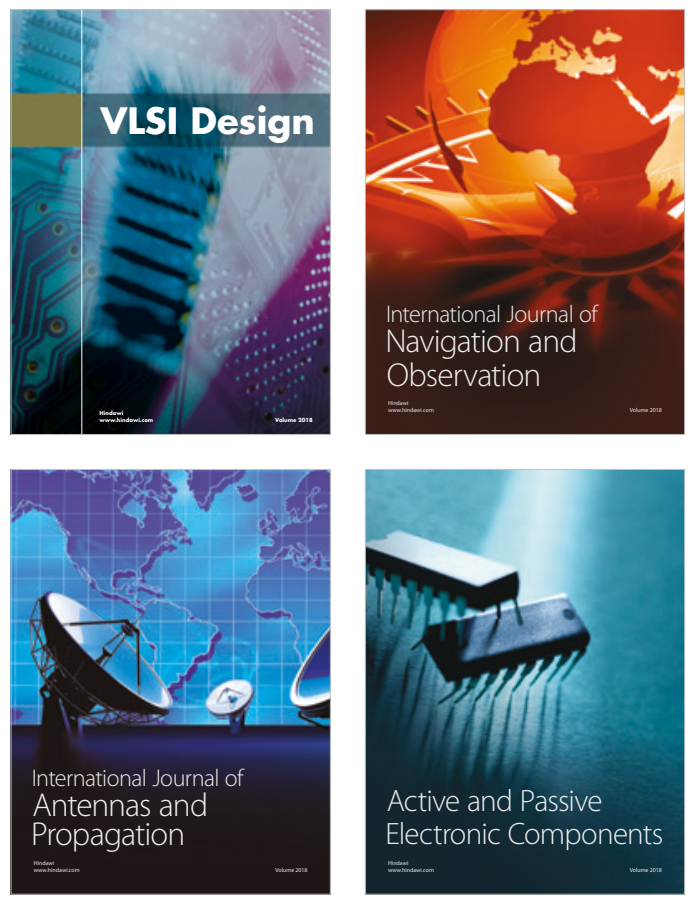
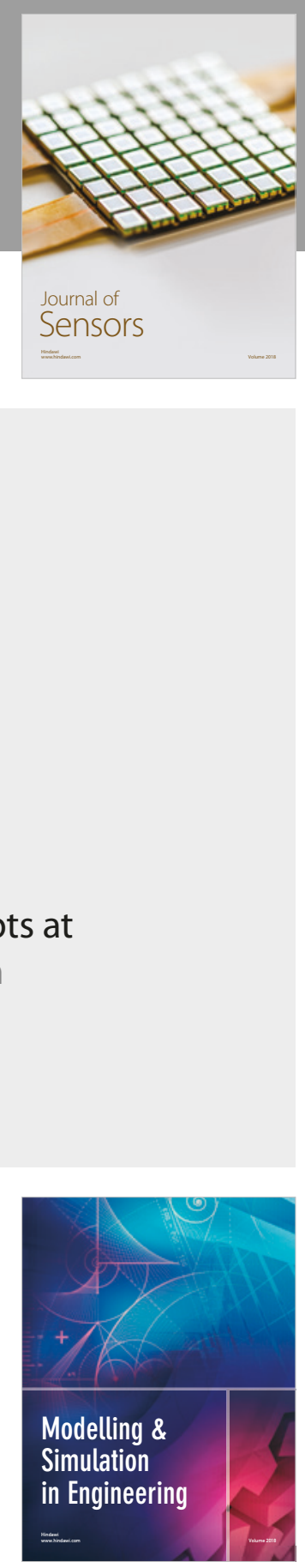

\section{Advances \\ Multimedia}
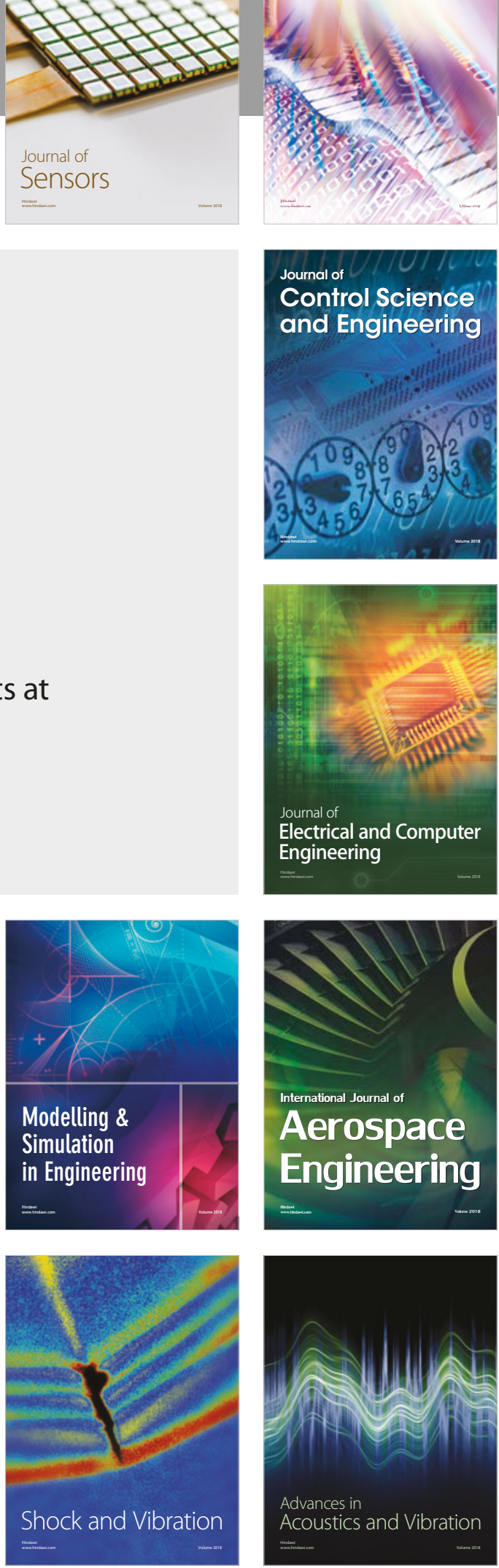